\title{
Real-time metrology with BSO crystals
}

\author{
H. J. TIZIANI \\ Institut für Technische Optik, Universität Stuttgart, \\ Pfaffenwaldring 9, 7000 Stuttgart 80, F.R. Germany
}

(Received 17 November 1981)

\begin{abstract}
Electro-optical crystals are used for real-time holography, optical data storage, optical information processing and more recently for speckle applications. Many ferro-electric materials were investigated, the $\mathrm{Bi}_{12} \mathrm{SiO}_{20}$ (BSO), a cubic, para-electric and electro-optic material was found to be very useful for real-time holographic interferometry and speckle applications. For the application of the BSO in real-time metrology, the crystals is usually biased with a transverse electric field in the 110 or 100 crystallographic direction. Illuminating the crystal with spatially structured information in the $\mathbf{T} 10$ direction as a result of a hologram or speckle pattern, a space charge field is built up, leading to a refractive index variation in the crystal. Double-exposure techniques and time average exposure will be presented for real-time deformation displacement and vibration analysis and for contour line holography using a two-wavelengths method.

Young's fringes of double-exposed, or in the time-average recorded speckle patterns will be attractive for real-time deformation displacement and vibration analysis.
\end{abstract}

\section{Introduction}

Storage materials in holography, holographic interferometry and speckle photography are mainly photographic materials based on silver halide. Possible alternatives are photoresist, dichromated gelatin, photochromic or thermoplastic materials, or electro-optical crystals.

Electro-optical crystals are discussed in this paper. Ferro-electric storage material such as $\mathrm{Fe}$ doped $\mathrm{LiNbO}_{3}$ offers good storage capacity, high read-out efficiency, high resolution and reversibility, but has a low sensitivity. By contrast, Ba $\mathrm{TiO}_{3}$ is very sensitive to light, but is too slow as far as the response time is concerned. Promising electro-optical materials are bismuth silicon oxide, $\mathrm{Bi}_{12} \mathrm{SiO}_{20}(\mathrm{BSO})$, and bismuth germanium oxide $\mathrm{Bi}_{12} \mathrm{GeO}_{20}(\mathrm{BGO})$. The writing energy for a diffraction efficiency of 1 per cent is of the order of $0.3 \mathrm{~mJ} / \mathrm{cm}^{2}$ for BSO and $1.2 \mathrm{~mJ} / \mathrm{cm}^{2}$ for BGO at $\lambda=514 \mathrm{~nm}$ with a field applied of $E_{0}=6 \mathrm{kV} / \mathrm{cm}$ as compared with $30 \mathrm{~mJ} / \mathrm{cm}^{2}$ for $\mathrm{LiNbO}_{3}$.

The BSO crystal is an attractive material for dynamic holographic experiments and phase-conjugate wave-front generation and real-time speckle photography. The specific applications to be discussed in the paper are real-time interferometry for deformation and vibration analysis and contour-line holography as well as speckle applications. [1-7].

For holographic interferometry and speckle-pattern recording the crystal is biased with a transverse electric field $E_{0}$ in the 110 cristallographic direction as indicated in figure 1. By recording the hologram or speckle pattern in the $\mathbf{T 1 0}$ direction, a space-charge field is built up. The recording medium contains donors and trapping centres. The electron released from donor centres are driven in the 


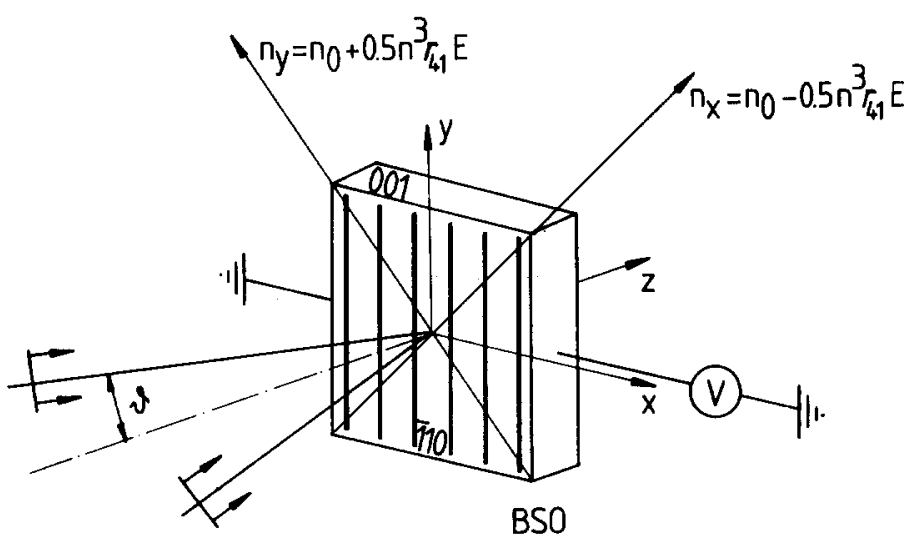

Figure 1. Crystallographic orientation for holographic recording in BSO crystals.

conduction band by diffusion or external applied field. Trapping of these charges leads to a space-charge field which modulates the birefringence through linear electro-optic effect, leading to a phase-volume recording. Flooding with uniform illumination with the recording wavelength leads to the erasure of the stored information by space-charge relaxation. Consequently, reading out with the recording wavelength is destructive.

The BSOs used were mostly sensitive in the blue-green spectral region. A redsensitive crystal was also used in some experiments. The transverse electric field applied was $6 \mathrm{kV} / \mathrm{cm}$ and the dark-storage time was found to be 30 hours. The grating diffraction efficiency is of the order of 1 per cent for an applied electric field of $6 \mathrm{kV} / \mathrm{cm}$.

\section{Real-time holographic applications with BSO crystals}

A typical arrangement for real-time holography and holographic interferometry is shown in figure 2. The interference patterns of the object wave and coherent planereference wave are stored in the crystal. By retroreflection of the plane-reference

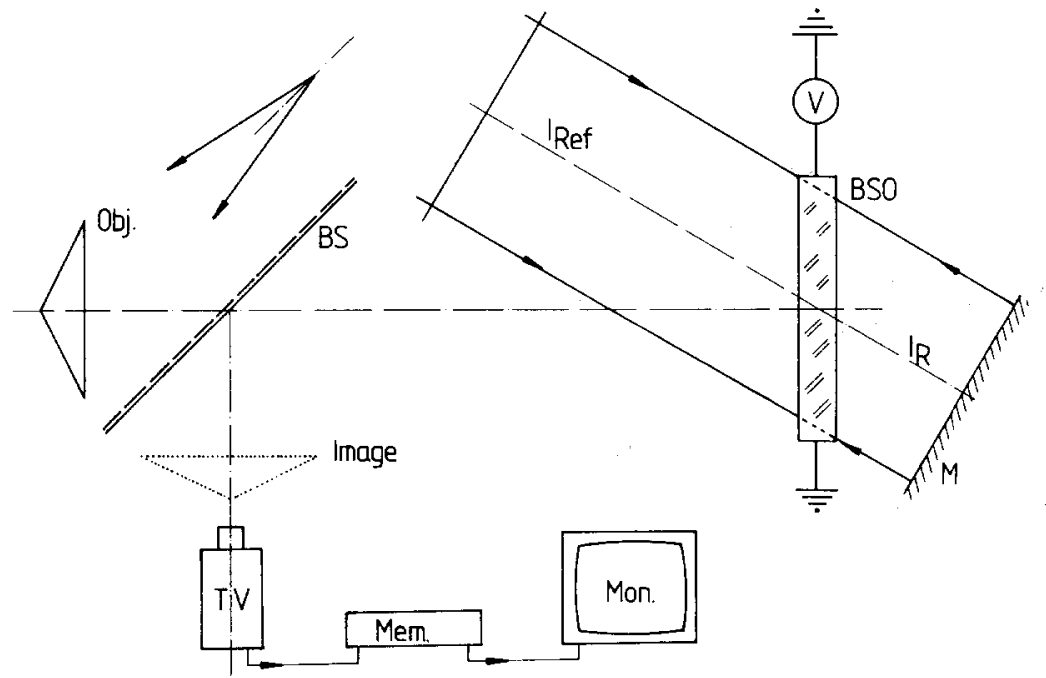

Figure 2. Experimental apparatus for holography and holographic interferometry. 


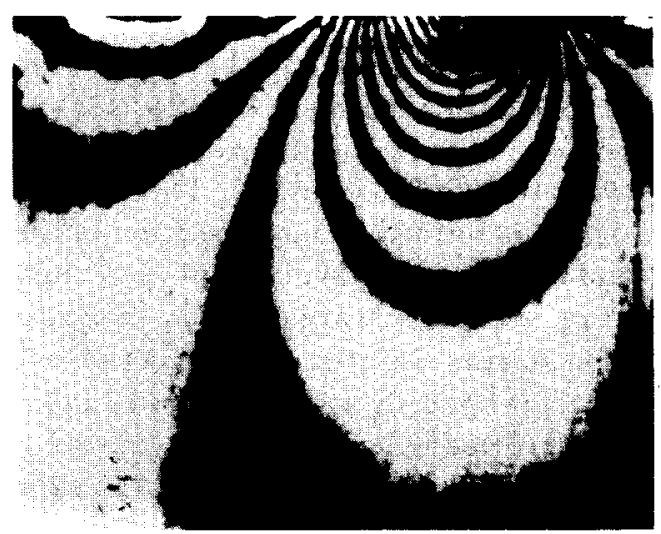

Figure 3. Fringe pattern of the real-time reconstruction of a double-exposed hologram with a deformation between.

wave, the phase-conjugate wave front of the object wave is reconstructed in realtime. Therefore, the reconstructed wave front is not only reflected but is the phaseconjugate, allowing imaging through phase disturbing media [11].

For real-time holographic interferometry, using double-exposure technique, the object wave is at first stored in the crystal. The second exposure takes places after the object deformation. Reconstructing the original and deformed wave fronts leads to interference fringes related to the deformation [3]. Fringes occur after the second exposure has taken place, see figure 3 . A harmonically vibrating object recorded in the time average leads to the time-average fringe pattern in quasi-real-time. Figure 4 shows the result of a vibrating membrane recorded in the time average in the BSO. A storage tube was used for automatic fringe analysis. In figure 4 the exposure time was of the order of $1 \mathrm{~s}$, and the frequency of oscillation was $500 \mathrm{~Hz}$. The time constant to build up the hologram to saturation needs to be long compared with the vibration period [8]. The dark fringes correspond to the zero of the Bessel function $J_{0}$. The intensity $I$ is given by:

$$
I \propto J_{0}^{2}\left(\frac{4 \pi \rho}{\lambda}\right),
$$

for $\rho$, the amplitude of vibration, and $\lambda$, the wavelength.

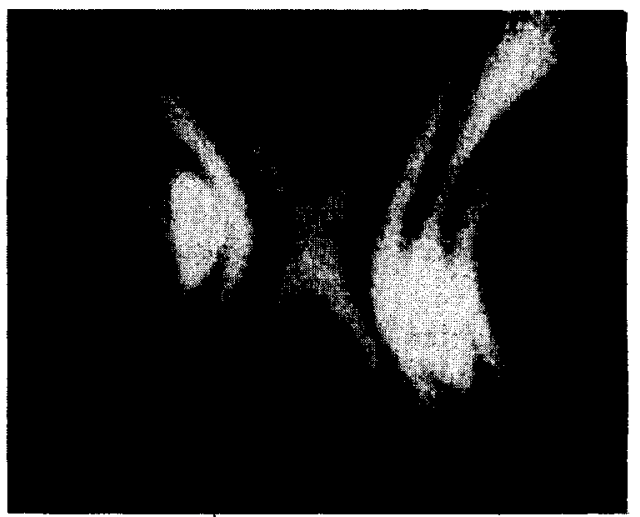

Figure 4. Fringe pattern of an oscillating loudspeaker at $500 \mathrm{~Hz}$. 


\section{Real-time contour-line holography}

Contour-line holography in real-time can be a powerful tool for contactless measurements. An experimental arrangement with the $\mathrm{BSO}$ as storage material and a two-wavelengths technique is shown in figure $\mathbf{5}$ when the object is illuminated simultaneously with two wavelengths, $\lambda_{1}$ and $\lambda_{2}$. The angle of the incidence-plane wave was $\theta_{q}$. The hologram is formed by superposition of the image of the object formed via $L_{1}$ and $L_{2}$ and the reference wave containing $\lambda_{1}$ and $\lambda_{2}$. By reconstructing the phase-conjugate wave, either the wavelength $\lambda_{1}$ or $\lambda_{2}$ can be selected by the appropriate angle of the mirror, i.e. the reconstruction will satisfy the Bragg condition. Since the crystal is optically active, unwanted light can be blocked with the analyser $\mathrm{A}$. The reconstructed image wave fronts travel backwards through the telescope and are coupled out with a beam splitter as shown in figure 5 . The separation of the contour lines [7] for $f_{1} / f_{2} \sin \theta_{q}=\sin \theta_{r}$ is

$$
\Delta z=\frac{\lambda_{1} \lambda_{2}}{\left(1+\cos \theta_{q}\right)\left(\lambda_{1}-\lambda_{2}\right)},
$$

where $\lambda_{1}, \lambda_{2}$ are the wavelengths used and $\theta_{q}$ and $\theta_{r}$ are the angles of incidence for the illuminating and reference waves. $f_{1}$ and $f_{2}$ are the focal lengths of $\mathrm{L}_{1}$ and $\mathrm{L}_{2}$.

With the configuration chosen, no grating for compensating the angles for the two wavelengths of the reference wave is needed [9]. Moreover, the angles $\theta_{q}$ and $\theta_{r}$ can be small and the telescope lenses can then be used for collimation.

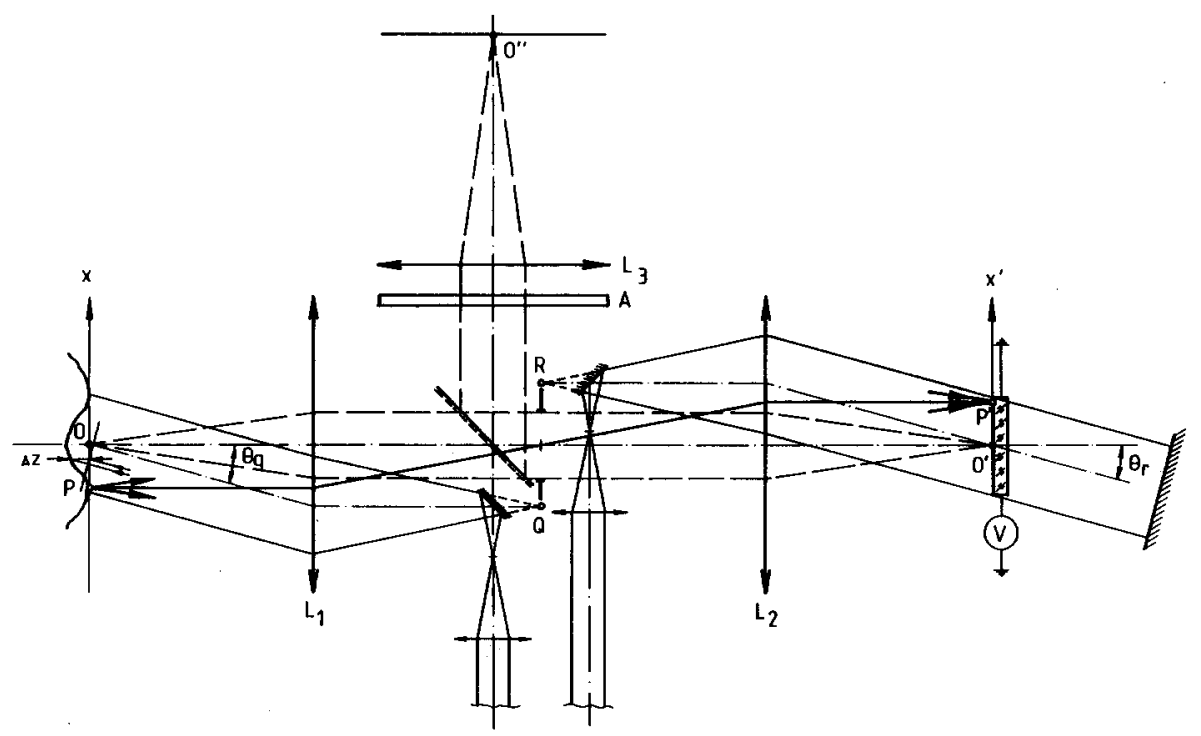

Figure 5. Experimental apparatus for real-time contour-line holography with a twowavelengths technique.

In figure $6(a)$ the reconstruction of a metallic surface is shown, and in figure $6(b)$ the real-time contour lines were obtained for $\Delta z=13.9 \mu \mathrm{m} \quad\left(\lambda_{1}=520.83 \mathrm{~nm}\right.$, $\lambda_{2}=530.87 \mathrm{~nm}$ of a krypton-ion-laser). The separation of the contour lines can be selected by choosing the appropriate wavelength pair of a krypton or argon laser. The adjustment of the object is carried out in real time. For figure 7 , the object was illuminated with two pairs of $\lambda$, namely $\lambda_{1}=476.24 \mathrm{~nm}$ and $\lambda_{2}=482.52 \mathrm{~nm}$ leading to 


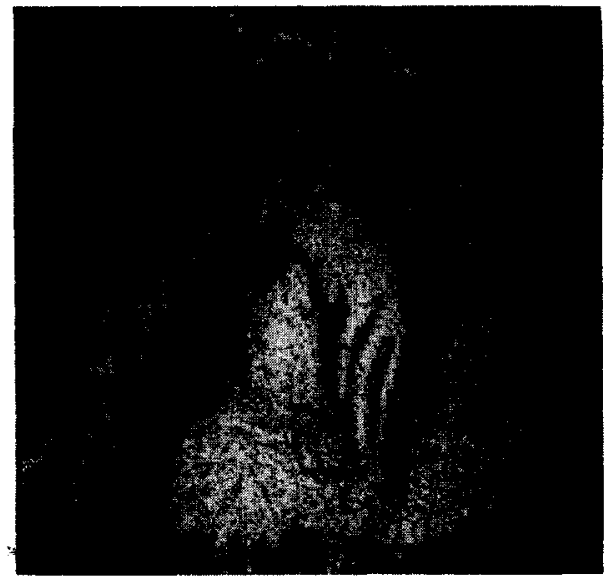

(a)

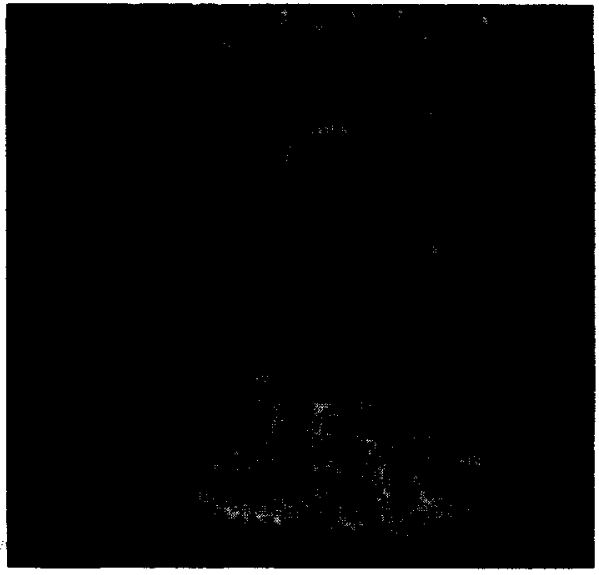

(b)

Figure 6. (a) Reconstruction of a metallic coin. (b) Reconstruction of the metallic coin with contour lines of $\Delta z=13.9 \mu \mathrm{m}$.

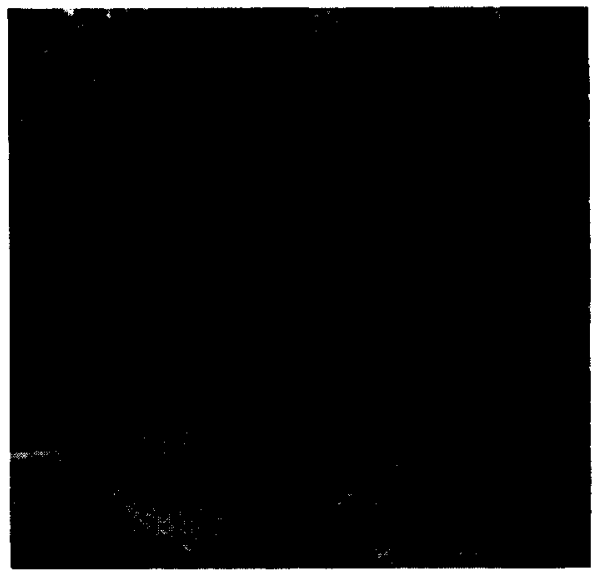

Figure 7. Reconstruction of a metallic object with contour lines of $\Delta z_{1}=18.45 \mu \mathrm{m}$ and $\Delta z_{2}=2 \cdot 7 \mu \mathrm{m}$.

$\Delta z=18.45 \mu \mathrm{m}$ and $\lambda_{2}=482.52 \mathrm{~nm}$ and $\lambda_{3}=530.87 \mathrm{~nm}$, giving $\Delta z=2.7 \mu \mathrm{m}$. Two sets of contour lines are clearly visible in figure 7 .

\section{Real-time speckle applications with BSO crystals}

Real-time speckle photography was found to be very promising for analysis of deformation, tilt and displacement [5], or for time-average recording for vibration analysis [6]. The experimental layout is shown in figure 8. For the double-exposure technique, the speckle patterns are recorded before and after the deformation or displacement, leading to pairs of speckle patterns recorded in the crystal with the wavelength $\lambda_{1}$. Of course, no reference wave is needed for the speckle-pattern recording. For displaying the Young's interference fringes in the Fraunhofer plane, the wavelength $\lambda_{2}$ was used. The absorption of the BSO for $\lambda_{1}=514 \mathrm{~nm}$ is $2 \mathrm{~cm}^{-1}$, and for $\lambda_{2}=633 \mathrm{~nm}$ is $0.28 \mathrm{~cm}^{-1}$. Therefore, no storage device is needed for the speckle technique. For the automated fringe analysis, TV technique can be used as 


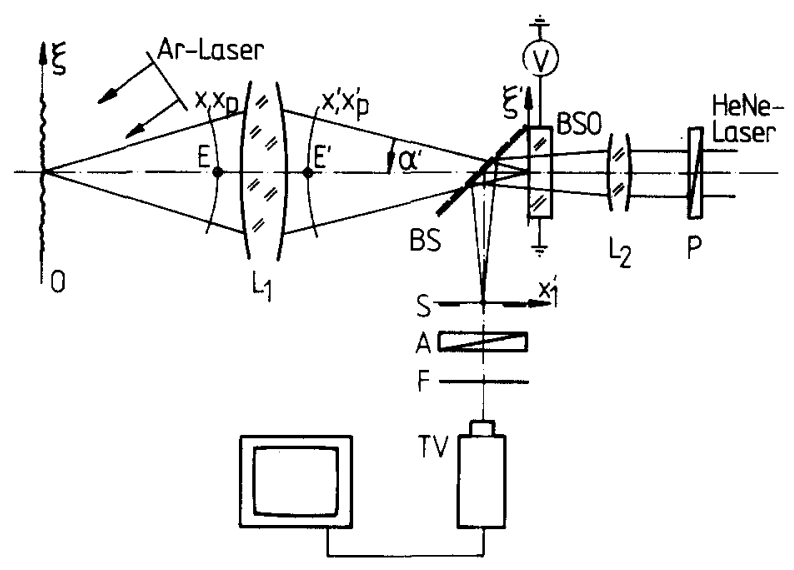

Figure 8. Experimental arrangement for real-time speckle applications.

indicated in figure 8. For tilt analysis, the BSO is placed in the back focal plane of the lens $\mathrm{L}_{1}[10]$ or in the image of the source. Figure 9 shows the results of a real-time tilt analysis with a tilt of 26 arc sec between the two exposures.

For a harmonically oscillating object the speckle pattern can be recorded in the time average in the BSO. Fringes obtained in this way, in the Fraunhofer plane, no longer follow a cosine-square law but the square of the Bessel function, of order zero and first kind $[6,10]$. From the minima of the Bessel function, the amplitude of oscillation can be found. In figure 10 the fringes for a metallic object oscillating in the plane at a frequency of nearly $1 \mathrm{kHz}$ with an amplitude of $47 \mu \mathrm{m}$ is shown. Fringes were obtained $1 \mathrm{~s}$ after starting the exposure. For comparison, figure 11 shows the fringe pattern obtained from the same harmonically oscillating object recorded on the thermoplastic material.

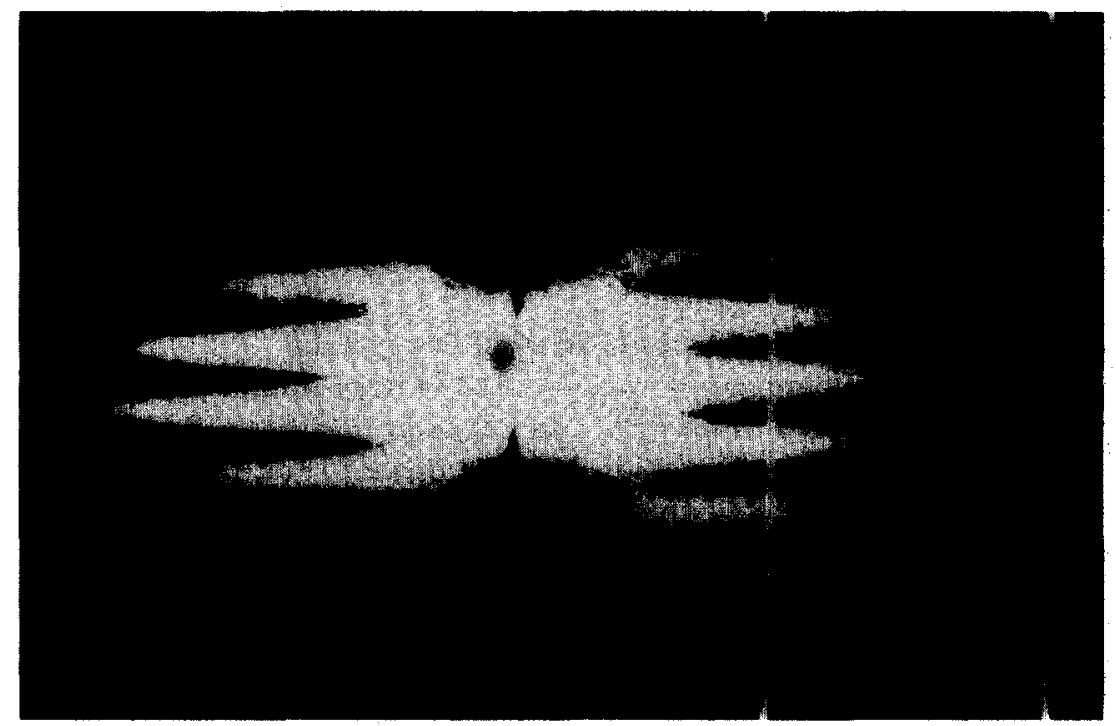

Figure 9. Real-time Young's fringes of a tilt of 26 arc second between the two exposures. 


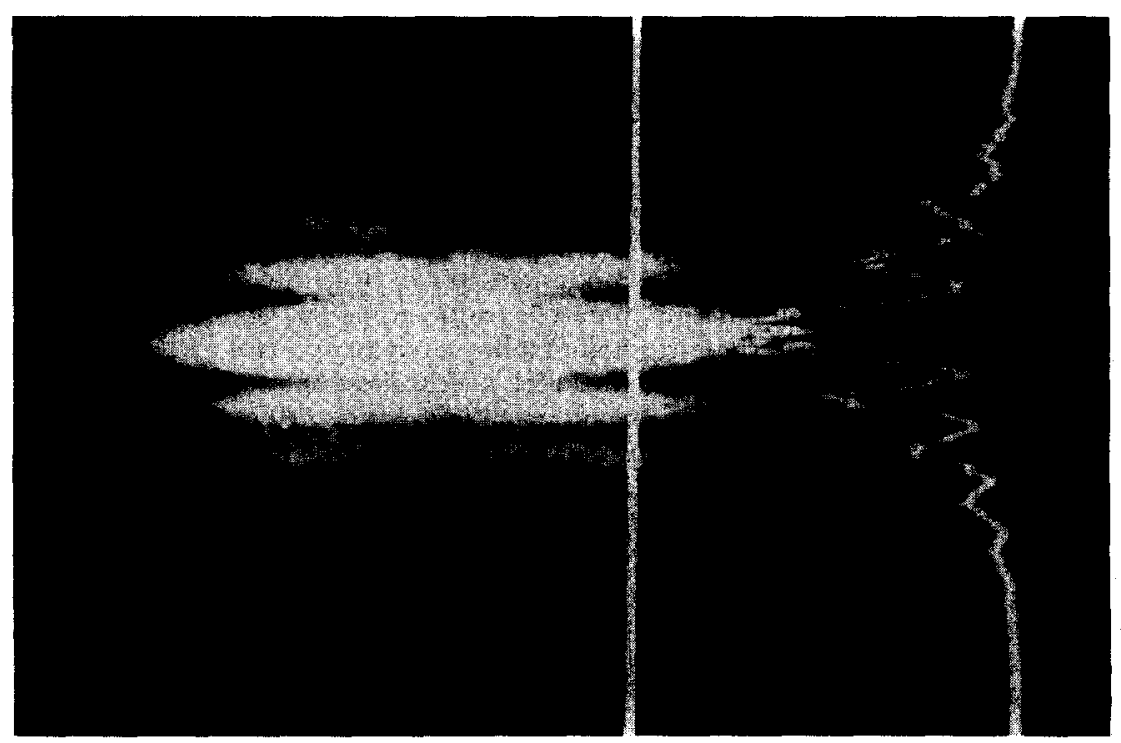

Figure 10. Fringes of a speckle recording in the time average of a harmonically oscillating metallic object with amplitude of vibration of $47 \mu \mathrm{m}$.

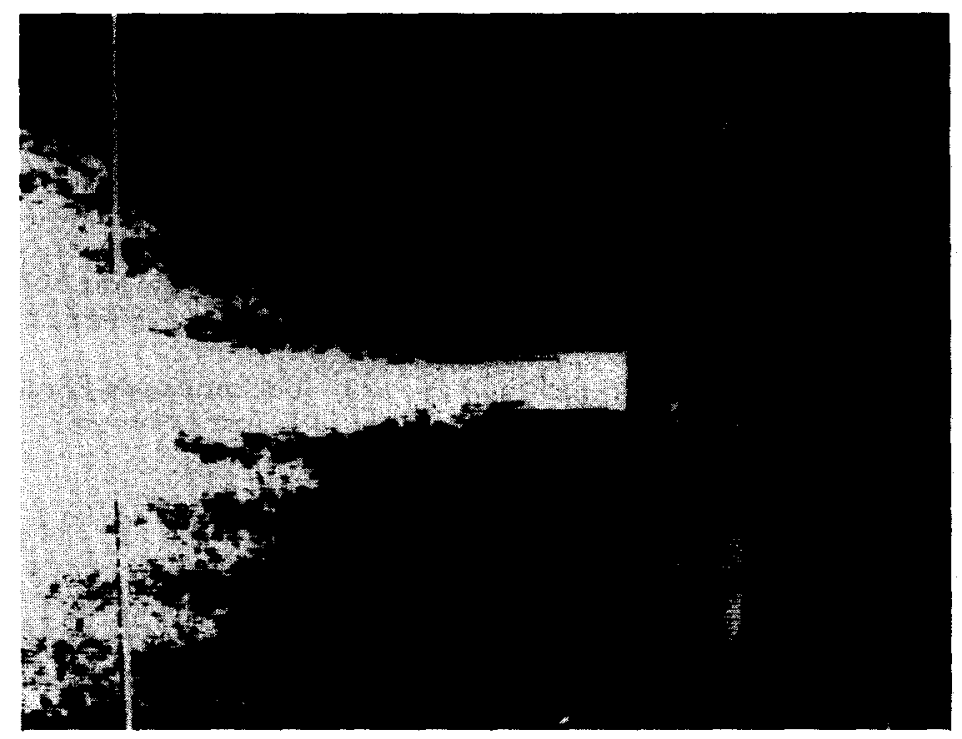

Figure 11. Fringes of a time-average speckle recording on thermoplastic material for the oscillating object of figure 10 .

\section{Conclusions}

Electro-optical crystals were found very useful for quasi-real-time contactless measuring techniques. The BSO appears to be particularly attractive for in-situ interferometry and speckle applications. The experiments take advantage of the high photographic sensitivity and short time constant for recording and erasure. The material is continuously reusable without any fatigue effect. 


\section{Acknowledgments}

The author would like to thank M. Küchel and J. Klenk for carrying out some of the experiments and the DFG for financial support.

Des cristaux électro-optiques sont utilisés pour l'holographie en temps réel, le stockage de données optiques, le traitement d'information optique et, plus récemment, pour des applications au speckle. De nombreux matériaux ferro-électriques ont été étudiés; le $\mathrm{Bi}_{12} \mathrm{SiO}_{20}$ (BSO), un matériau cubique, para-électrique et électro-optique a été considéré comme très utile pour l'interférométrie holographique en temps réel et le speckle. Pour l'application du BSO à la métrologie en temps réel, le cristal est habituellement soumis à un champ électrique transverse dans la direction cristallographique 110 ou 100. En éclairant le cristal dans la direction $\mathbf{1} 10$ par une information spatialement structurée provenant d'une figure d'holographie ou de speckle, un champ de charges d'espace apparaît, conduisant à des variations de l'indice de réfraction dans le cristal. Des techniques de double exposition et d'exposittion en temps moyenné sont présentées pour des analyses èn temps réel de déformations, de déplacements et de vibrations ainsi que pour l'holographie à ligne de contour en utilisant une méthode à deux longueurs d'onde.

Les franges d'Young de double exposition ou de figures de speckle enregistrées en temps moyenné sont intéressantes pour des analyses en temps réel de déformations, de déplacements et de vibrations.

Elektro-optische Kristalle werden für Real-Time-Holographie, optische Datenspeicherung, optische Informationsverarbeitung und neuerdings für SpeckleAnwendungen benutzt. Viele ferroelektrische Materialien wurden untersucht, das $\mathrm{Bi}_{12} \mathrm{SiO}_{20}$ (BSO), ein kubisches, paraelektrisches und elektrooptisches Material, erwies sich als sehr nützlich für holographische Interferometrie in Echtzeit und für Speckle-Anwendungen. Für die Anwendung von BSO in der Echtzeit-Meßtechnik wird der Kristall gewöhnlich mit einem transversalen elektrischen Feld in der kristallographischen 110 oder 100 Richtung vorgespannt. Beleuchtung des Kristalls in der $\overline{1} 10$ Richtung mit einer durch ein Hologramm oder durch ein Specklemuster erzeugten räumlich strukturierten Information baut ein Raumladungsfeld auf, weiches zu einer Brechungsindexmodulation im Kristall führt. Doppelbelichtungstechniken und Zeitmittelungsbelichtung werden für die Verformungsund Schwingungsanalyse in Echtzeit, sowie für die Niveaulinienholographie nach der ZweiWellenlängen-Methode präsentiert.

Youngsche Streifen von Doppelbelichtungs- und Zeitmittelungs-Specklemustern werden für die Deformations- und Schwingungsanalyse in Echtzeit attraktiv.

\section{References}

[1] Glass, A. M., 1978, Opt. Lett., 5, 470.

[2] Yariv, Y., 1978, Optics Commun., 25, 23.

[3] Huignard, J. P., and Herriau, J. P., 1977, Appl. Optics., 16, 1807.

[4] Marrakchi, A., Huignard, J. P., and Herriau, J. P., 1980, Optics Commun., 34, 15.

[5] Tiziani, H. J., Leonhardt, K., and Klenk, J., 1980, Optics Commun., 34, 327.

[6] Tiziani, H. J., and Klenk, J., 1981, Appl. Optics, 20, 1467.

[7] Küchel, M., Tiziani, H. J., 1981, Optics Commun., 38, 17.

[8] Powell, R., and Stetson, K., 1965, J. opt. Soc. Am., 55, 1593.

[9] Haines, K. A., and Hilderrand, B. P., 1967, J. opt. Soc. Am., 57, 155.

[10] Tiziani, H. J., 1978, Speckle Metrology, edited by R. K. Erf (New York, London: Academic Press), p. 73.

[11] Huignard, J. P., 1981, Current Trends in Optics, edited by F. T. Arecchi and F. R. Aussenegg (London: Taylor \& Francis Ltd), p. 150. 